\title{
К ВОПРОСУ СООТНОШЕНИЯ СОДЕРЖАТЕЛЬНОЙ И ОБСЛУЖИВАЮЩЕЙ (ВСПОМОГАТЕЛЬНОЙ) ДЕЯТЕЛЬНОСТИ СПЕЦИАЛИСТОВ В ОРГАНАХ УПРАВЛЕНИЯ ОБРАЗОВАНИЕМ
}

\section{ON THE RATIO BETWEEN THE SUBSTANTIAL AND SERVICE (AUXILIARY) ACTIVITIES OF SPECIALISTS IN EDUCATION MANAGEMENT BODIES}

A. Korol

Summary: The article deals with the ratio between the "substantial» and «service» ("auxiliary») activity of specialists in education management bodies of the regional, municipal and school levels. A common pattern of transformation of the structure and staffing depending on introduction of new competencies, functions and powers of a government institution, caused by changes in legislation, has been discovered based on the example of evolution of the government educational management institution of the Khabarovsk Territory. The article substantiates and proves the expediency of the introduction of a new model construction for individual fundamental documents which regulate activities of educational institutions as legal entities, based on segregation of invariant and variable components of the documents.

Keywords: education management bodies, legislation, powers, competencies, education organization statute, civil rights, legal entity, invariant component of a document, variable component of a document.
Король Александр Михайлович к.п.н., дочент, ФГБОУ ВО «Тихоокеанский государственный университет», г. Хабаровск kor_kor2001@mail.ru

Аннотация: В статье анализируется соотношение «содержательной» и «0бслуживающей» («вспомогательной») деятельности специалистов в органах управления образованием регионального, муниципального и школьного уровней. На примере эволюции государственного органа, осуществляющего управление в сфере образования Хабаровского края, выявляется закономерность трансформации структуры и штатного расписания в зависимости от закрепления за органом новых компетенций, функций и полномочий в связи с изменением действующего законодательства. Обосновывается возможность и доказывается целесообразность внедрения новой модельной конструкции отдельных основополагающих документов, регламентирующих деятельность образовательных организаций как юридических лиц, предполагающей выделение инвариантной и вариативной частей документов.

Ключевые слова: орган управления образованием, закон, полномочия, компетенции, устав образовательной организации, гражданское право, юридическое лицо, инвариантная часть документа, вариативная часть документа.
$\Pi$ очти 30 лет назад в результате прекращения существования СССР наша страна вынужденно вступила в эпоху глобальных потрясений и реформ в политической, экономической и социальной жизни.

В этот непростой период становления новой российской государственности в стране происходило выстраивание вертикали управления, в том числе в сфере образования. В наследство от СССР от советской системы народного образования регионам достались региональные отделы образования при краевых (областных, республиканских) исполнительных комитетах и районные (городские) отделы образования на местах. К примеру, в Хабаровском крае на базе отдела образования исполнительного комитета краевого Совета народных депутатов в начале 1992 года был образован комитет образования администрации Хабаровского края (далее - комитет образования), а в районах края и городах Хабаровске и Комсомольске-на-Амуре - 26 отделов образования администраций районов (городов).

Следует отметить, что комитет образования в 1992 году представлял собой достаточно немногочисленную структуру, состоящую из 5 отделов (отдел общего и дополнительного образования детей - 6 человек, отдел учреждений общественного воспитания - 4 человека, планово-финансовый отдел - 4 человека, отдел кадрового обеспечения - 4 человека, отдел координации общего, профессионального образования и науки - 2 человека), группы технического надзора - 4 человека, особого отдела - 1 человек, канцелярии - 4 человека, централизованной бухгалтерии (на правах подведомственного учреждения) - 5 человек. В качестве обособленного подразделения в структуре администрации края было выделено отдельно управление профессионального образования со своей бухгалтерией, планово-финансовым отделом. Должность юристконсульта (юриста) в комитете образования отсутствовала.

Осуществляя свою деятельность, система образования остро нуждалась в нормативно-правовой базе, регулирующей основные правоотношения участников образовательного процесса в формирующейся парадигме рынка. 
В июле 1992 года автор настоящей статьи, имея полномочия представлять интересы комитета образования в федеральных органах власти, был направлен в командировку в г.Москву с целью получить консультации по перспективам формирования отраслевого нормативноправового поля (напомним, что в то время сети Интернет ещё не было). Волею случая в «коридорах власти» ему посчастливилось встретить члена Верховного Совета Российской Федерации от Республики Тувы Алтая Николаевича Пиче-оола, который передал Хабаровскому краю распечатанный на лазерном принтере экземпляр только что принятого закона Российской Федерации «Об образовании» (от 10 июля 1992 г. № 3266-1, введен в действие Постановлением Верховного Совета Российской Федерации «О порядке введения в действие закона Российской Федерации «Об образовании» от 10 июля 1992 г. № 3267-1). За время обратного перелёта из Москвы в Хабаровск текст закона был перечитан несколько раз с карандашом в руке, а большинство статей закона были выучены практически наизусть.

Следует отметить, что этот долгожданный закон едва ли не впервые в истории права Российской Федерации разграничил компетенции, функции и полномочия в области образования между уровнями власти. Законом установлено много новелл, осмысление и реализация которых потребовало определённого времени, повлекло разработку множества подзаконных актов, инструкций и рекомендаций.

Дальнейшему развитию основных положений законодательства в области образования послужило принятие федеральных законов, постановлений Правительства Российской Федерации, распорядительных актов федеральных органов, осуществляющих управление в сфере образования.

В связи с необходимостью ликвидации наметившегося разрыва между имеющимся законодательным обеспечением правоотношений в сфере образования и реальными потребностями складывающейся образовательной практики был принят и действует в настоящее время с изменениями и дополнениями новый федеральный закон от 29 декабря 2012 года № 273-Ф3 «Об образовании в Российской Федерации».

Вполне естественно появление новых полномочий и функций приводит к эволюционированию управленческих структур в сфере образования. Так в региональных органах управления образованием появились новые структурные подразделения, занимающиеся вопросами государственной регламентации образовательной деятельности (лицензирование, аттестация, государственная аккредитация), информатизации образования, правового сопровождения, ресурсного обеспечения, оказания государственных и муниципальных услуг в сфере образования, государственных и муниципальных закупок, координации высшего образования и науки и т.д. При этом рост штатной численности этих обеспечивающих структур похож на экспоненциальный (в отличие от фиксированной численности «содержательных» структурных подразделений).

Ныне органом исполнительной власти Хабаровского края, осуществляющим управление в сфере образования и науки, а также полномочия по организации и осуществлению в крае деятельности по опеке и попечительству в отношении несовершеннолетних и координирующим в пределах своей компетенции деятельность в этих сферах других краевых органов исполнительной власти и органов местного самоуправления, является министерство образования и науки Хабаровского края. В его структуру входят уже не отделы, а целые управления с достаточно большим количеством специалистов (управление планирования, финансирования и контроля; управление государственной регламентации образовательной деятельности; управление опеки и попечительства, защиты прав и интересов детей; управление профессионального образования; управление общего и дополнительного образования; управление инфраструктуры, имущественного комплекса и информатизации образования; управление опеки и попечительства, защиты прав и интересов детей; управление правовой работы и организации государственных закупок; управление организационно-кадровой и аналитической работы). Поддержку и сопровождение деятельности министерства образования и науки края осуществляют несколько подведомственных (не образовательных) организаций: краевое государственное казенное учреждение «Центр по развитию семейных форм устройства детей, оставшихся без попечения родителей, и постинтернатному сопровождению», краевое государственное казенное учреждение «Региональный центр оценки качества образования», краевое государственное казенное учреждение «Центр бухгалтерского учета и ресурсно-правового обеспечения образования».

При этом центр тяжести управленческой деятельности министерства образования и науки края смещается на управление не столь образовательными процессами, сколь вспомогательными (для сравнения см. выше - описание структуры комитета образования администрации края).

Аналогичная ситуация наблюдается и в других регионах страны.

Вполне возможно цивилизованная управленческая деятельность органа управления образованием в условиях сформированного в стране нормативного правово- 
го поля и разветвлённой сети подведомственных образовательных организаций, которым частично переданы управленческие функции по тому или иному вопросу, такой и должна быть? Но возникает вполне резонные вопросы:

- не потеряем ли мы на региональном уровне из виду собственно само содержание образования с методиками изучения предметов, формами, методами и дидактическими приёмами преподавания?

- каким образом складывающийся дисбаланс между «содержательными» и «обеспечивающими» («вспомогательными») функциями в управлении образованием региона декомпозируется на нижестоящие уровни управления, вплоть до руководителя образовательной организации?

Отвечая на первый вопрос, выскажем своё мнение, что риск переноса на «задний план» содержательных вопросов образования в управленческих структурах имеется. Желающие могут убедиться в этом, проанализировав в сети Интернет или правовых базах «КонсультантПлюс» или «Гарант» тематику коллегий региональных органов управления образованием и заседаний региональных администраций (правительств) - в своём большинстве превалируют рассматриваемые вопросы, посвящённые формально-статистическим показателям развития образовательных систем и обеспечения их жизнедеятельности.

По-хорошему, функции распространения передового педагогического опыта, изложенного в многочисленных диссертационных работах, публикациях в научных и научно-методических журналах, должны взять на себя региональные институты повышения квалификации (институты развития образования). Но функциями принятия управленческих решений эти организации не наделены, да и качество повышения квалификации учителей в этих структурах вызывает сомнение, особенно когда повышение квалификации сводится к пересказам вузовских учебников. Получается, что на уровне регионов нет механизма доведения до педагогов и управленческих работников результатов современных педагогических исследований. А региональные чиновники, имеющие полномочия принимать управленческие решения по созданию условий для распространения передового педагогического опыта, не имеют времени читать хотя бы соответствующие реферативные издания. Долгие годы назрел, но остаётся открытым вопрос о модернизации региональных и муниципальных методических служб.

Для ответа на второй вопрос достаточно изучить структуру муниципальных органов управления образованием, которая ориентирована, в основном, исключительно на полномочия, определённые законодательством. При этом обеспечивающие и вспомогательные функции в муниципальном органе доминируют над содержательными, что проявляется не только в планах работы и муниципальных программах развития, но и в «тяжеловесных» и во многом искусственных согласовательных процедурах.

В качестве примера рассмотрим процедуру согласования и утверждения устава образовательной организации. Устав регламентирует деятельность образовательной организации как юридического лица. Требования к нему определены в статьях 25, 26, 27, 30, 34, 44, 47, 51, 57 федерального закона «Об образовании в Российской Федерации», а также в статьях 9.2, 14, 28 Федерального закона «О некоммерческих организациях». На практике согласование этого документа (или согласование внесения в него изменений и дополнений) учредителем представляет собой достаточно длительную процедуру - порядка месяца. При наличии в регионе большого числа подведомственных образовательных организаций приведение в соответствие с текущим законодательством новых редакций уставов растягивается надолго. При этом в процесс согласования включены не только содержательные специалисты, но и юристы, экономисты и иные специалисты органа управления образованием органа управления финансами, органа управления имуществом. А ведь зачастую образовательным организациям приходится вносить изменения и дополнения в уставы по несколько раз в год.

Ранее были приняты и широко применялись на практике типовые положения о соответствующих типах и видах образовательных учреждений, что позволяло основную часть текста типового положения взять за основу устава. Собственно, и сейчас многие образовательные организации используют тексты утративших силу типовых положений для разработки уставов. Более того - прежнее законодательство позволяло образовательному учреждению действовать на основе типового положения без разработки своего устава. Сейчас это возможно лишь для казенного учреждения.

Принятие устава и внесение в него изменений и дополнений является, безусловно, необходимой работой, обеспечивающей институционализацию образовательной организации как юридического лица и как субъекта гражданских прав и обязанностей. Но когда деятельность многих государственных и муниципальных служащих, причастных к этой работе, превращается в «юридическое искусство» ради соблюдения канонов юридической техники, приводя к отвлечению времени, сил и внимания на не столь значимые, а порою и формальные вопросы, это уже вызывает вопросы.

Напомним, что именно закон Российской Федерации «Об образовании» 1992 года, положивший основы граж- 
данских правоотношений в образовании, продекларировал, что образовательное учреждение является юридическим лицом. Потребовалось более 10 лет, что бы в стране была завершена работа по приданию образовательным организациям статуса юридических лиц (письмо Министерства образования Российской Федерации от 14 июня 2000 года № 22-06-687 «О государственной регистрации образовательных учреждений как юридических лиц»). В настоящее время все образовательные организации в Российской Федерации имеют статус юридических лиц, обладая всеми их признаками, обозначенными в статье 48 Гражданского Кодекса Российской Федерации.

Не будучи специалистами в области гражданского права и не покушаясь на основы законодательства, регулирующего гражданские правоотношения юридических лиц, позволим себе внести на обсуждение предложение, реализация которого позволит найти внутренние резервы системы образования за счет оптимизации работ по согласованию учредительных документов.

Суть этих предложений заключается в том, чтобы представить устав образовательной организации из двух частей - инвариантной и вариативной. Анализ текстов уставов многих образовательных организаций, размещённых в свободном доступе, свидетельствует о том, что значительная часть статей (разделов) повторяется практически неизменной. Содержание этих статей (разделов) уставов либо дублируют отдельные положения действующего законодательства, либо носят декларативный характер, либо заимствованы из недействующего типового положения об общеобразовательном учреждении. Если юристы считают, что наличие таких статей (разделов) является необходимым в уставе, то их можно доработать, унифицировать и предложить в качестве инвариантного раздела устава, который должен быть утвержден учредителем один раз и для всех образовательных организаций соответствующего типа.

Вариативная часть устава должна представлять собой статьи (разделы), учитывающие особенности конкретной образовательной организации. Не трудно понять, что регистрировать нужно именно вариативную часть устава.

Данное предложение не нарушает конструкцию действующего законодательства в области гражданского права. Его реализация никак не отразится на статусе юридического лица образовательной организации. Более того, руководителям образовательных организаций, специалистам учредителя, представителям контролирующих организаций будет значительно облегчена работа с документом. Существенно сократится срок его согласования, уставы могут стать действительно основными документами, регламентирующими деятельность образовательной организации (в настоящее время многие уставы просто дублируют установленные законодательством права и свободы участников образовательного процесса).

Еще одним примером неэффективной работы обеспечивающих структур органов управления образованием является работа с федеральным законом от 5 апреля 2013 года №44-Ф3 «О контрактной системе в сфере закупок товаров, работ, услуг для обеспечения государственных и муниципальных нужд». Переводится впустую большое количество принтерной краски и офисной бумаги для распечатки дублирующих законодательство положений конкурсной документации.

Мы считаем, что в конкурсной документации также можно выделить инвариантную (одинаковую для всех образовательных организаций) и вариативную часть. Инвариантную часть можно утвердить вышестоящим органом один раз для всех подведомственных организаций. Вариативная же часть должна определяться конкретным заказчиком для конкретной закупки.

Таких примеров, когда школьный (районный, городской, областной) документ можно представить в виде совокупности инвариантной и вариативной части в отрасли «Образование» можно привести много. К их числу можно отнести в том числе всевозможные локальные акты образовательных организаций. Министерству просвещения Российской Федерации необходимо провести инвентаризацию имеющейся нормативной правовой базы на предмет целесообразности выделения инвариантных и вариативных разделов. Централизация разработки инвариантной части многих документов позволит не только улучшить их качество, но и сократить время неэффективной работы специалистов обслуживающих и вспомогательных подразделений органов управления образованием.

Реализация внесённых предложений не так сложна. Если на федеральном уровне будет принят предложенный концепт, то дело остаётся «за малым» - внести соответствующие изменения в законодательство и подзаконные акты. Конечно, как и любая работа по оптимизации законодательства, это потребует определённых усилий. Зато в итоге будет упорядочена деятельность обслуживающих и вспомогательных структурных подразделений государственных и муниципальных органов, осуществляющих управление в сфере образования, будет облегчена работа руководителей образовательных организаций, и, со временем, возможно будет восстановлен статус-кво «содержательных» специалистов от образования. 


\section{ЛИТЕРАТУРА}

1. Онлайн-версия КонсультантПлюс: [Электронный ресурс]. - Режим доступа: http://www.consultant.ru/ (дата обращения: 06.07.2020).

2. Письмо Министерства образования Российской Федерации от 14 июня 2000 года № 22-06-687 «0 государственной регистрации образовательных учреждений как юридических лиц» [Электронный ресурс]. - Режим доступа: http://docs.cntd.ru/document/901772306 (дата обращения: 06.07.2020).

3. Юридические лица: типы, виды, организационно-правовые формы : учеб. пособие / [Т.Л. Калачева и др. ; под ред. Т.Л. Калачевой]. - Хабаровск : Изд-во Тихоокеан. гос. ун-та, 2018. -96 с.

( Король Александр Михайлович (kor_kor2001@mail.ru).

Журнал «Современная наука: актуальные проблемы теории и практики»

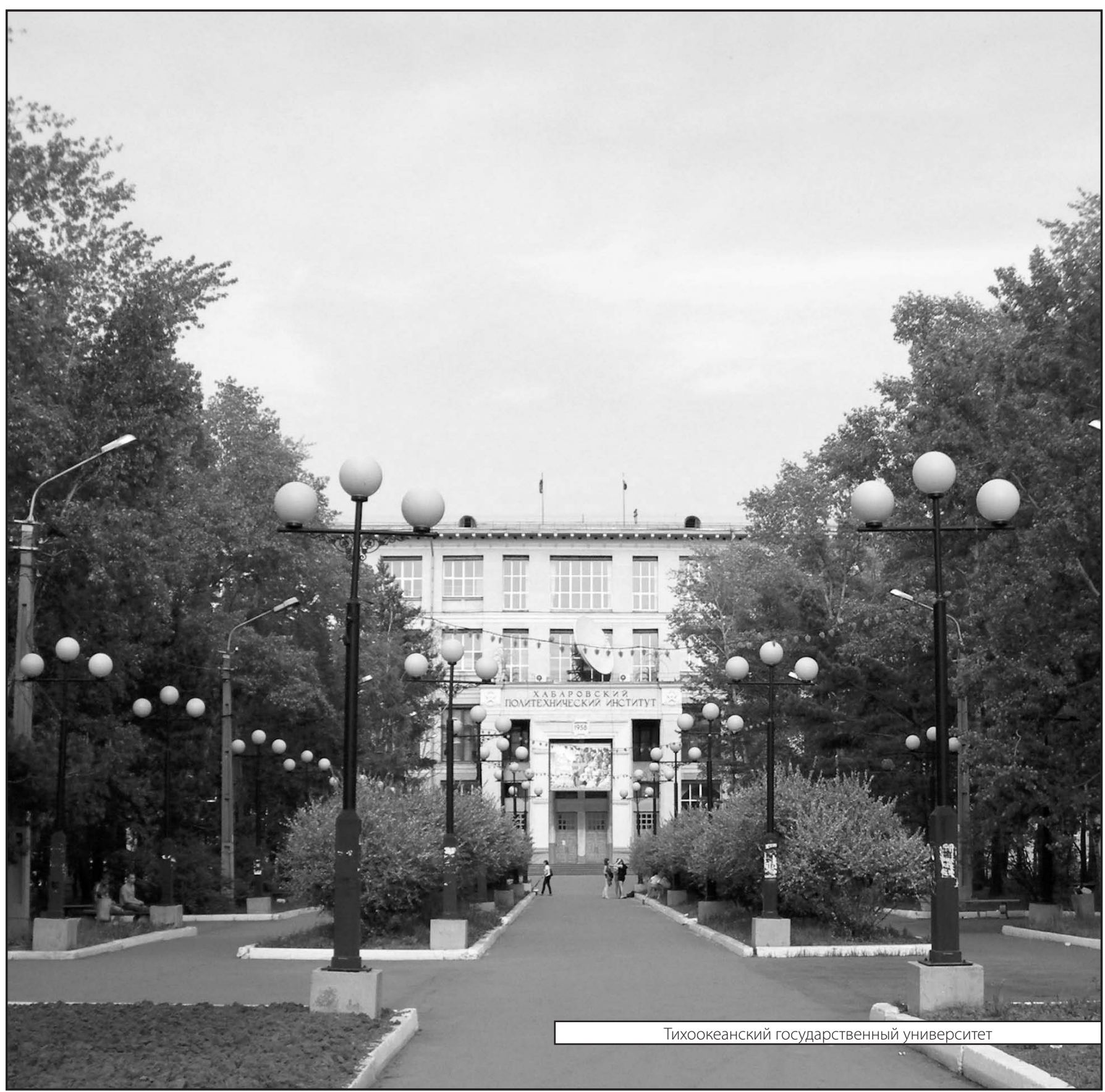

